This is an author produced version of a paper published in Construction and Frames. This paper has been peer-reviewed but does not include the final publisher proof-corrections or journal pagination.

Citation for the published paper:

Wärnsby, Anna. (2016). On the Adequacy of constructionist approach to modality. Construction and Frames, vol. 8, issue 1, p. null

URL: https://doi.org/10.1075/cf.8.1.03war

Publisher: John Benjamins

This document has been downloaded from MUEP (https://muep.mah.se) / DIVA (https://mau.diva-portal.org). 


\title{
On the adequacy of a constructionist approach to modality \\ Anna Wärnsby
}

\begin{abstract}
When speakers are confronted with modal expressions in their native language, specifically those that contain a modal verb, they are able to interpret these expressions as epistemic or non-epistemic, for example. But what enables the speakers to interpret these modal expressions instantly and accurately despite the inevitably complex explanation any linguistic theory needs to evoke to account for this? Modality, modals and modal interpretations are among those universal tension points where the explanatory value of any theoretical construct is sorely tested.

This paper raises some questions about the adequacy of applying Construction Grammar (Goldberg 1995, 2006) as a method of analysis of expressions containing modal verbs. In particular, the following issues are discussed: (i) the necessity to postulate a great number of constructions to account for a modal utterance, (ii) the theoretically unrestricted scope of a construction, and (iii) the ever-present problem of indeterminate modal utterances.
\end{abstract}

\section{Introduction}

When asked to present this paper in a special issue devoted to the analyses of modal utterances within the Construction Grammar, I hesitated since I have never really worked within this theoretical framework, having dismissed it as an adequate tool for the analysis of modal utterances some years ago. After revisiting my own work and that of others, I was rather surprised to find myself still holding the view that Construction Grammar (as presented in Goldberg 1995, 2006) has little explanatory value when it comes to the analysis of modal utterances. In this paper, I raise some more general questions about Construction Grammar as a method for the analysis of modal utterances.

That Construction Grammar can be used for the analysis of modal utterances has been shown unequivocally by many: Bert Cappelle and Ilse Depraetere (2014), Alexander Bergs (2010), and Ronny Boogaart (2009), to mention just a few. However, despite such insightful suggestions, the arguments as to why Construction Grammar should be used for the analysis of modal utterances are still not obvious. My reasons for scepticism are firstly, a very detailed description is needed to account for the abundance and relatedness of modal constructions; secondly, the role of context as well as what contextual features are to be included in a modal construction is not yet fully formalised; thirdly, although it is widely accepted that constructions can be placed along a 
continuum from lexical to schematic, how the scope of, particularly schematic, constructions is handled within this theoretical framework is rarely explicitly discussed; and finally, it is still unclear how Construction Grammar proposes to deal with the phenomena of indeterminacy, underdeterminacy, ambiguity or vagueness, if you wish, which is so prevalent in languages and in modal utterances in particular.

\section{Brief overview of the theoretical tenets}

Within Construction Grammar, the meaning of an expression is seen as "the result of integrating the meanings of the lexical items into the meanings of constructions" (Goldberg 1995, p. 16), which "allows both broad generalizations and more limited patterns to be analysed and accounted for fully" (Goldberg 2006, p. 3). What is a construction, then? According to an early definition, a construction is:

$\mathrm{C}$ is a constriction iff $_{\text {def }} \mathrm{C}$ is a form-meaning pair $\left\langle\mathrm{F}_{i}, \mathrm{~S}_{i}\right\rangle$ such that some aspect of $\mathrm{F}_{i}$ or some aspect of $\mathrm{S}_{i}$ is not strictly predictable from C's component parts or from other previously established constructions. (Goldberg 1995, p. 4)

Further elaboration on the nature of constructions is provided by Cruse and Croft (1999, p. 28), who discuss constructions in terms of being "atomic" and "complex," consisting of "morphologically bound" as well as "morphologically free" parts, which may be "substantive" (containing lexical items such as $[s k y]$ ) and "schematic" (containing information about what elements may enter a construction such as [S V-TNS OBJ $\left.{ }_{1} \mathrm{OBJ}_{2}\right]$ ). Moreover, like any item in the lexicon, constructions are allowed to be polysemous. Goldberg (1995, p. 31) suggests that constructions can have several related senses possibly organised around a central or prototypical sense.

In Goldberg (2006), the definition of a construction is made seemingly simpler: constructions are described as "learned pairings of form with semantic or discourse function, including morphemes or words, idioms, partially lexically filled and fully general phrasal patterns." Moreover,

[a]ny linguistic pattern is recognized as a construction as long as some aspect of its form or function is not strictly predictable from its component parts or from other constructions recognized to exist. In addition, patterns are stored as constructions even if they are fully predictable as long as they occur with sufficient frequency. (Goldberg 2006, p. 5) 
Stronger claims are thus made in the later version of the framework on the nature of language organisation and its acquisition. These claims differ radically from those adopted, for example, by the generative school; many of the arguments Goldberg develops in her 1995 and 2006 books are devoted to clarifying the nature of this disagreement. Thus instead of arguing for the existence of some genetically determined language faculty or for the distinction between separate modulessuch as syntax, semantics, phonology and a lexicon which contains semantic/syntactic information about lexemes-construction grammarians view language as "a network of constructions" in which grammatical and semantic knowledge is codified (Cruse \& Croft 1999, p. 1). In fact, Construction Grammar assumes a syntax-lexicon continuum; it postulates the existence of lexical and syntactic constructions which "differ in internal complexity, and also in the extent to which phonological form is specified", but which are essentially "the same type of [...] data structure: both pair form and meaning" (Goldberg 1996, p. 7). Although these arguments promote Construction Grammar as a model for processing linguistic structures (see also Hilpert 2014), much less is said about how it works as a production model. General cognitive constraints paired with the functions of constructions at hand are claimed to account for the cross-linguistic generalisations observed elsewhere (Goldberg 2006, pp. 17-18). Further, language acquisition is said to be triggered by "positive input together with fairly general cognitive abilities": "analogical processes," "the ability to record transitional probabilities and statistical generalizations," as well as "constant indirect negative evidence that helps [children] to recover from overgeneralizations" (Goldberg 2006, p. 15). The merit of these more general theoretical claims is addressed in Adger (2013) and is not taken up here.

The different types of constructions are claimed to be structured to accommodate "systematic generalizations across constructions" (Goldberg 1996, p. 67). Constructions are also said to be taxonomically related or linked to each other ${ }^{1}$, which allows for the network of constructions rather than a strict hierarchy. The four major types of these inheritance links, which enable one construction to inherit some particular information from another (dominating) construction, are as follows: (i) polysemy links (capture the nature of the semantic relations between a particular sense of a construction and any extensions from this sense, for example, the ditransitive construction in English); (ii) metaphorical extension links (relate two constructions by metaphorical mapping, for example, caused motion and resultative constructions); (iii) subpart links (are stated when one construction is a proper subpart of another construction and exists independently, for example, the Subject in a verbal construction); and (iv) instance links (posited

\footnotetext{
${ }^{1}$ Michaelis and Lambrecht (1996) refer to this type of relations between the constructions as "inheritance hierarchies."
} 
when one construction is a more fully specified version of another construction) (Goldberg 1996. pp. 75-81). This is further elaborated in Trousdale (2013, p. 491), who demonstrates that not only can "[i]nheritance relationships [be] used to describe synchronic facts about a language whereby members of a less abstract set inherit properties from a more general set, and in the case of multiple inheritance, from more than one general set" but that they can also be appealed to explicate diachronic facts.

\section{Modal constructions and inheritance relations}

Examining modal data, it is possible to conclude that epistemic utterances systematically differ from non-epistemic ones (see, for example, Coates 1983, Wärnsby 2006). In Wärnsby (2002), 13 modal utterance types with epistemic interpretation were shown to differ in terms of syntactic/semantic environments from non-epistemic utterances. Consequently, 13 epistemic modal constructions were proposed for English in accordance with the Principle of No Synonymy outlined in Goldberg (1996, p. 67). These constructions are to a certain degree empirically motivated and come from a detailed analysis of 361 random examples of utterances containing the modal may previously extracted from the English-Swedish Parallel Corpus ${ }^{2}$. Let us examine one of these epistemic constructions, namely the [NP $\mathrm{MAYe}^{3}$ state], which is possibly a particular instantiation of a [NP MODe state] construction, parented in turn by a more schematic [NP MOD state]. In fact, [NP MAYe state] dominates at least six more specified constructions:

(1) [NP MAYe Vstate]

"I may have something for you that you'll like even more," said Harcourt-Smith. ${ }^{4}$

\section{(2) [NP MAYe BE AjP]}

We have fragments from papers by Aeschines the Socratic and Antisthenes the Cynic that tell us Socrates really lived, and which may be spurious.

\section{(3) [NP MAYe BE NP]}

Only a little; but it may be the thin edge of the wedge, the crack in the wall that will open, later, onto what?

\footnotetext{
2 The corpus is not parsed nor tagged; consequently, no more in-depth statistical analysis nor collostrational analysis were possible at the time the study was conducted.

${ }^{3}$ The graphic representation of the epistemic interpretation on the modal (MAYe and MODe) is a mere matter of convenience as the modal arguably would lend itself a more natural host for modal interpretation than any other element in these constructions.

${ }^{4}$ Unless indicated otherwise, the examples were extracted from the originals in the English-Swedish Parallel Corpus.
} 
(4) [NP MAYe BE VenSTATE]

Or it may be parked somewhere in Ipswich.

This may well be considered tall by some races, such as the Asians whose average height is less than this, but not by others.

(5) [NP AUX BE Ving]

Yes, very clever, darling, but I rather think I may be bleeding.

We may all of us be being punished now for sins we are about to commit.

(6) [NP AUX BE CompCl]

What's turned up may not be as bad as you think.

These constructions are syntactically distinct, and, according to Goldberg's definition of pragmatic aspects, which includes "particulars of information structure [...] and additional stylistic aspects of the construction such as register" (1996, p. 67), they are pragmatically synonymous. In addition, we have already identified these constructions as epistemic; and by virtue of being epistemic, they are also semantically synonymous. ${ }^{5}$

According to Cruse and Croft (1999, pp. 32-33), if we include modal elements into constructions, "then any construction in the hierarchy [will have] multiple parents," much like the "multiple inheritance" described in Trousdale (2013). This means that it is possible to postulate a construction consisting of the modal may, possibly even with the specification 'epistemic' [MAY(e)] and, for example, a predicate adjective construction [NP BE AjP], which will both parent the construction [NP MAYe BE AjP]. The modal meaning of the construction will possibly be inherited from the more general modal construction [MODe], and the predicate adjective construction will provide the modal construction with the meaning of some property being predicated of the Subject. This more general epistemic construction will have to be an instance of an even more schematic modal construction [MOD]. Even the "simple" predicate adjective construction will have to have at least two parents: (i) the copula be construction (different from but related to that which requires combination with an NP), and (ii) an adjective construction which requires to be combined with the copula construction (which is again different but related to the prenominal adjective construction).

\footnotetext{
${ }^{5}$ Goldberg (1996, p. 108), however, dismisses such claims by stating that "the existence of a given form with a particular meaning in no way motivates the existence of a different form with a closely related meaning. Therefore, inheritance links are not posited between constructions that are not related formally".
} 
By now I have mentioned at least seven possible constructions that could be needed in a construction network defining the epistemic adjective modal construction. But what happens if all the networks for the variety of epistemic modal constructions are taken into account as well as other modal constructions including modal adverbials, modal adjectives and other means of expressing modality in English? What we then face is a bewildering web of constructions "generalized to encompass the full range of grammatical knowledge of a speaker" (Cruse \& Croft 1999, p. 27). Goldberg (2006, p. 10) finds such a rich description unproblematic: “An actual expression typically involves the combination of at least half a dozen different constructions." Even if "actual expressions" are understood narrowly as "the product of combining various kinds of grammatical chunks (constructions), which are recycled in various ways, ${ }^{, 6}$ how this may affect our understanding of modal utterances as constructions is not clear. For example, whether the modals are to be seen as contributing to grammatical or semantic content has never really been resolved. In standard linguistic descriptions (Quirk, Greenbaum, Leech \& Svartvik 1985; Biber, Johansson, Leech, Conrad \& Finegan 1999; Huddleston \& Pullum 2002), modals fall under the grammatical category of auxiliary verbs (by having certain grammatical properties, e.g. NICE-properties), but their peculiar semantic properties are attributed to their residual meanings (cf. Traugott 1989). This suggests that the description of modal utterances as constructions may be at least as complex as the notion of modality itself. Construction Grammar is then an adequate descriptive tool, but it does not seem to facilitate generalisations about the modals. This, however, may be true for any linguistic theory attempting to explicate modal utterances and interpretations, not necessarily because of theoretical inadequacies but because of the complexity of the object under scrutiny.

But what would the exact contribution of these modal parent constructions be anyway? Will these constructions determine the modal interpretation itself? Or will they somehow combine with the other parents to ascertain the epistemic interpretation? And in that case, how? To compare, facing a somewhat similar problem of more or less unconventional uses of intransitive verbs in transitive constructions like He sneezed the napkin off the table, Construction Grammar offers an elegant and well-motivated solution. Since the caused-motion interpretation does not reside in the verb sneeze, it must necessarily be coerced by the context provided in the construction itself: the Caused-motion Construction [SUBJ [V OBJ OBL]] (Goldberg 1995, p. 172). Thus "[o]ne of the central arguments for positing meaningful constructions that exist independently of the words which instantiate them stems from the wish to avoid the claim that the syntax and semantics of the clause is projected exclusively from the specifications of the main verb" (Goldberg 1995, p. 224). This frees us from the necessity of positing "implausible verb senses for cases in which verbs occur in an

\footnotetext{
${ }^{6}$ Thanks to the anonymous reviewer for this explanation.
} 
unusual environment [...]" (Boas 2013, p. 4). Is there an equally motivated reason for postulating meaningful modal constructions? What implausibilities or what prototypicalities are we trying to capture? For example, choosing a prototypical epistemic modal construction and claiming that this construction is somehow quantificationally and thus psychologically predominant (see Bybee 2007) will not offer a better insight into modal use since there is nothing inherently more or less epistemic in any of the constructions in (1-6).

\section{Modal constructions and context}

On the other hand, an investigation into the contexts in which the English modals appear reveals some interesting regularity. Figure 1 displays a so-called decision tree that resulted from a data mining analysis of the examples from the English-Swedish Parallel Corpus mentioned previously. This decision tree predicts modal interpretation on the basis of the patterning of contextual features in these modal utterances; the prediction is accurate in almost $80 \%$ of the cases.

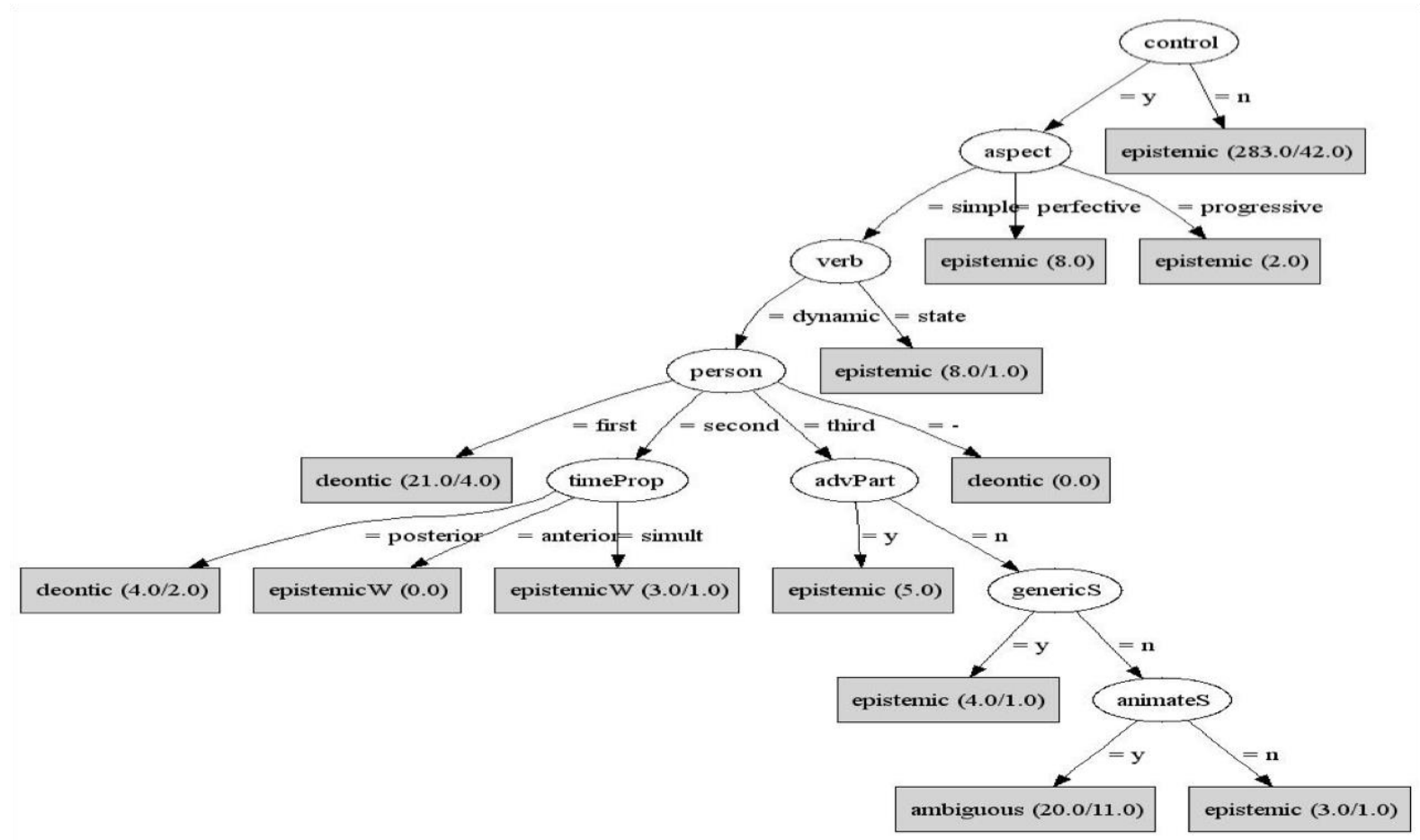

Figure 1. The decision tree for may. (Wärnsby 2006:182)

The contextual features in the decision tree singled out to contribute to the modal interpretation of the utterances containing may are controllability, aspectual modification, verb type, how the subject is expressed, and time reference for the proposition. In most cases where the subject referent is not in control of his or her actions, the preferred interpretation is epistemic. If the subject referent is in control, a combination of other features must be considered as well. For example, if the subject referent is in control but the utterance is aspectually modified, the interpretation of this utterance is 
likely to be epistemic. On the other hand, in cases where the subject referent is in control and the aspect is simple, the type of a verb in the modal utterance - whether stative or dynamic - becomes important. Some of the features are explicit, but some may be implicit and derived from the context. Some of the features are related to each other in terms of some hierarchy or taxonomy, while some of the features are seemingly unrelated. This is discussed in detail in Wärnsby (2006, pp. 180-186).

There is, however, enough systematicity found in Wärnsby (2006) in the contexts for modal verbs to be tempted to postulate a number of modal constructions to reflect this. However, potentially, there are many constructions to be mined here. The question is whether cataloguing them all would really add to our understanding of modality and explain how modal interpretation arises. As Klinge (1993, p. 318) argues, "[t]he recurring problem for linguistic analyses of the modals has been the lack of a principled account of how we arrive at an explicit interpretation of a sentence containing a modal." A constructionist analysis attempted of examples (1-6) is rather dubious since distinguishing epistemic constructions from non-epistemic ones is not addressed. As the general disagreement about the polysemy or the monosemy of the modals (see, for example, Kratzer 1977, Coates 1983, Papafragou 1998, 2000) is not principally settled within the Construction Grammar framework, any analysis involving the modals within this framework will at most provide a rich description of the data. It is therefore difficult to see what Construction Grammar, at least in the version presented in Goldberg 1995 and 2006, contributes to the analysis of modal expressions that has not been suggested within other frameworks ${ }^{7}$. Even if the "sister theory" of Construction Grammar, namely Frame Semantics (Fillmore 1982), is considered, this description is not significantly altered. What is expressed in Martin's (1997, p. 71) explication of polysemy through frames, for example, is echoed closely in Papafragou's analysis of modality within Relevance theory: "Polysemy in frames ... not only stems from the fact that slots may be given different prominence-or may assume different perspectives—in a relational knowledge cluster, but also from the fact that they are not yet fully specified expectation patterns which get their full semantic value by means of their fillers."

\footnotetext{
${ }^{7}$ Other versions of Construction grammar have, with various degrees of success and formalism, incorporated Fillmore's idea of frames, which allows for a more comprehensive analysis of the modals. These approaches, however, fall outside the scope of this paper.
} 


\section{Modal constructions and constructional scope}

As mentioned above, Construction Grammar postulates a form-meaning continuum along which languages are organised. The nature of constructions along this continuum varies, from more lexically determined to more schematic. This adds greatly to the description of linguistic structures and also makes sense, for example, from a language acquisition perspective (see, for example, Tomasello 2003), although conflicting accounts exist (Pinker 2007, 2013). Further, the current and established way to teach a foreign language to young children is to first teach them chunks in order to unpack them later into more manageable building blocks (see Cameron 2001, Lundahl 2014, Lundberg 2011).

However, neither the 1995 nor the 2006 definition of a construction places a limit to how comprehensive a construction can be. Based on Goldberg's argument that "the network of constructions captures our grammatical knowledge of language in toto, i.e. it's constructions all the way down" (2006, p. 18), the smallest construction is a word or a morpheme. However, nowhere does she talk about "the way up": how far can a construction reach in its most schematic form, how much of the contextual situation or world knowledge needs to be made part of a construction, or how this is practically realised. Most of the constructions discussed in Goldberg $(1995,2006)$ are related to argument structure. Potentially, however, there will be a schematic construction not only for every syntactic notion that can be expressed in a language. When it comes to modals-whether one is to propose a constructionalist or a frame analysis—-situations in the world, including social conventions, register, genre and many other higher-order situational cues that may contribute to a construction in different ways must also be accounted for as these are arguably factors of importance for the interpretation ${ }^{8}$. Can these cues be considered constructions of their own right? Or are these factors that are somehow included in more manageably-sized phrasal and clausal constructions? If so, this is the opposite of the Chomskyan claim that language is epiphenomenal; here, the situational reality becomes secondary to the construction used to describe it.

Here are three examples where elements that are not necessarily linguistically realised but are derived from the broader context must be included in the postulated constructions. This may cause problems.

(7) The patient must have been mistreated. (Epistemic)

(8) The patient must have been mistreated to get compensation. (Deontic)

(9) I must be brave, I must maintain my own high standards. (Deontic)

\footnotetext{
${ }^{8}$ Compare to, for example, the much-longed-for formalisations of context in Sag (2012) and Fried (2009), or Boas (2001) arguments for frames in contrastive studies.
} 
Examples (7) and (8) are taken from Eide (2002, p. 238), where (7) is epistemic and (8) is deontic because there is a purpose clause that pushes the time reference for the proposition of the modal utterance forward relative to the time of the utterance, and I suppose we can postulate a family, or two, of constructions to account for both these examples. Thus the difference between the epistemic and non-epistemic modal constructions here may be that at least three constructions are parents of the non-epistemic modal construction (the non-epistemic modal construction, the perfective construction, and a purpose/condition construction which can in turn be expressed by a variety of constructions). If the meaning of the epistemic modal construction is constant, the differences between this construction and other epistemic constructions can be successfully accounted for in terms of the meanings contributed by the different parent constructions.

A problem, however, arises when such a purpose clause is implicit and derived from the previous discourse since constructions are posited on the basis of the elements present in an utterance. What about (9)? In its context, it is clearly deontic. The speaker is a prisoner who tells herself that in order to remain sane in his pitiful situation she must be brave. The purpose clause here is not expressed in the modal utterance itself, but it can easily be inferred from the context. A further complication is how to take our world knowledge into the construction to account for the fact that speakers rarely give themselves orders (this complication is encoded by the use of $I$, which can give rise to more particularised constructions involving this pronoun in similarly particularised contexts). Can we postulate implicit constructions to account for implicit purpose clauses? Should we?

Of course, we could try to construct an explanation along the lines of what has been argued about the Deprofiled Object Construction, as in Tigers kill at night. The verb kill licences two NParguments: the agent (the subject) and the patient (the object). Since it is assumed that tigers at night kill indiscriminately, the object, implicitly understood, is claimed to have low discourse prominence and can be omitted; thus " $[\mathrm{t}]$ he Deprofiled Object Construction serves a communicative function by shifting discourse prominence away from the patient argument, effectively licensing its omission" (Boas 2013, p. 8). However, implicit purpose clauses cannot be described as having low discourse prominence, so some other type of reasoning must be employed to do away with such implicit cues for the interpretation of modal utterances. What will this reasoning be?

\section{Modal constructions and indeterminacy}

My final concern using Construction Grammar in the analysis of the modals is the existence of indeterminate, underdeterminate, ambiguous or vague examples, or whatever term you prefer. 
(10) Tell us what it is to be a woman, so that we may know what it is to be a man.

(10) is ambiguous between the epistemic and deontic readings. It is either 'Tell us what it is to be a woman, so that it will be possible for us to know what it is to be a man' or 'Tell us what it is to be a woman, so that we are allowed (some kind of enablement) to know what it is to be a man.' To account for these two interpretations, one may be tempted to postulate two different constructions: [NP MODe Vstate] or [NP MODd Vstate]. The different interpretations are then prompted by the different modal parent constructions. But how do we know that in one case, one of the parents of the underlined construction is some epistemic modal construction and in the other case it is a deontic modal construction? Nothing is really gained with this description since the question of modal polysemy mentioned above remains unresolved. This is, however, a central issue in studying the modals, and any analysis must clearly demonstrate how it treats the issue of polysemy and this kind of ambiguity resolution.

\section{Conclusion}

To summarise, in this paper I expressed my concerns about Construction Grammar being a possible but not necessarily an adequate tool for the analysis of modality and modal verbs. Cataloguing the numerous modal constructions adds to the description of modality in a language, but it offers few possibilities for generalisation. Moreover, on a more general note, there are many claims about Construction Grammar offering a psychologically and cognitively real analysis of linguistic structure: Boas (2013) even calls his version of Construction Grammar Cognitive Construction Grammar. However, even more psycholinguistic research should be conducted before the bewildering web of constructions suggested by different researchers in different studies can be justified. Further, there are numerous suggestions about the lexical-schematic continuum along which constructions can be placed, but a lot of research is carried out on constructions localised within a clausal structure. In addition, the polysemy and the so often found indeterminacy of modal expressions cannot easily be explained within this theoretical framework.

One of the main theoretical tenets of cognitive linguistics as opposed the generative school is expressed in the following quote:

The model of language proposed by Cognitive Linguistics is so completely simple that it places the emphasis squarely on method and data. Rather than simplifying the object of study by carving off its complexities with hypothetic modules of language structure, it lands the linguist in the midst of a chaotic phenomenon that is the nature of all socially structured systems." (Glynn 2010, p. 2, the emphasis is mine) 
The data is out there, but whether the method is that of Construction Grammar can and should be discussed. That positing hypothetic modal constructions contributes to the description of modal data can not be denied. However, what it contributes to the analysis of these data is yet to be settled.

\section{References}

Adger, David. 2013. Constructions and Grammatical Explanation: Comments on Goldberg. Mind and Language, 28:4, pp. 466-478.

Bergs, Alexander. Expressions of Futurity in Contemporary English: A Construction Grammar Perspective. English Language and Linguistics, 14:2, pp. 217-238

Biber, Douglas, Johansson, Stig, Leech, Geoffrey, Conrad, Susan and Finegan Edward. 1999. Longman Grammar of Spoken and Written Language. London: Longman.

Boas, Hans C. 2001. Frame Semantics as a framework for describing polysemy and syntactic structures of English and German motion verbs in contrastive computational lexicography. Proceedings of corpus linguistics, 113, p. 144.

Boas, Hans C. 2013. Cognitive Construction Grammar. In Thomas Hoffmann and Graeme Trousdale (eds.), The Oxford Handbook of Construction Grammar. Oxford: Oxford University Press, pp. 233-254.

Boogart, Ronny. 2009. Semantics and Pragmatics in Construction Grammar: The Case of Modal Verbs. In Alexander Bergs and Gabriele Diewald (eds.), Contexts and Constructions. Amsterdam/Philiadelphia: John Benjamins, pp. 213-241.

Bybee, Joan. 2007. Frequency of Use and the Organization of Language. Oxford: Oxford University Press.

Cameron, Lynne. 2001. Teaching Languages to Young Learners. Cambridge: Cambridge University Press.

Cappelle, Bert and Depraetere, Ilse. 2014. Modal Meaning in Construction Grammar. The International Society for the Linguistics of English (ISLE) Conference, 24-27 August 2014, Zürich: Zürich University.

Coates, Jennifer. 1983. The Semantics of Modal Auxiliaries. London and Canberra: Croom Helm. Cruse, William and Croft, Allan, D. 1999. Cognitive Linguistics. Draft, version 6. Chapters 10-11. Eide, Kristin. M. 2002. Norwegian Modals. PhD dissertation. Department of linguistics, NTNU, Trondheim.

Fillmore, Charles. 1982. Frame Semantics. In Linguistic Society of Korea (ed.), Linguistics in the Morning Calm, pp. 111-138. Seoul: Hanshin. 
Fried, Mirjam. 2009. Representing Contextual Factors in Language Change: Between Frames and Constructions. In Alexander Bergs \& Gabriele Diewald (eds.), Contexts and Constructions, pp. 63-94. Amsterdam/Philadelphia: John Benjamins Publishing Company.

Glynn, Dylan. 2010. Corpus-driven Cognitive Semantics. An Introduction to the Field. In Dylan Glynn and Kerstin Fischer (eds.), Corpus-driven Cognitive Semantics. Quantitative Approaches, pp. 1-42. Berlin: Mouton de Gruyter.

Goldberg, Adele. 1995. A Construction Grammar Approach to Argument Structure. Chicago: The University of Chicago Press.

Goldberg, Adele. 2006. Constructions at Work: The Nature of Generalisation in Language. Oxford: Oxford University Press.

Hilpert, Martin. 2014. Construction Grammar and its Application to English. Edinburgh: Edinburgh University Press.

Huddleson, Rodney and Pullum Geoffrey K. 2002. The Cambridge Grammar of the English Language. Cambridge: Cambridge University Press.

Klinge, Alex. 1993. The English Modal Auxiliaries: From Lexical Semantics to Utterance Interpretation. Journal of Linguistics, 29:2, pp. 315-357.

Kratzer, Angelica. 1977. What 'Must' and 'Can' Must and Can Mean. Linguistics and Philosophy, 1, pp. 337-355.

Lundahl, Bo. 2014. Texts, Topics and Tasks: Teaching English in Years 4-6. Lund:

Studentlitteratur.

Lundberg, Gun. 2011. De Första Årens Engelska. Lund: Studentlitteratur.

Martin, Willy. 1997. A Frame-based Approach to Polysemy. In Cuyckens, Hubert and Zawada, Britta (eds.), Polysemy in Cognitive Linguistics. Selected Papers from the Fifth International Cognitive Linguistics Conference. Amsterdam: John Benjamins Publishing Company.

Michaelis, Laura A. and Lambrecht, Knud. 1996. Toward a Construction-based Theory of Language Function: The Case of Nominal Extraposition. Language, 72:2, pp. 215-247.

Papafragou, Anna.1998. Modality and Semantic Indeterminacy. In Rouchota, V and Jucker, A. H., Current Issues in Relevance Theory, pp. 237-270. Amsterdam: John Benjamins Publishing Company.

Papafragou, Anna. 2000. Modality: Issues in the Pragmatic-Semantic Interface. Amsterdam: Elsevier.

Pinker, Steven. 2007. The Language Instinct: How the Mind Creates Language (P.S.). New York: Harper Perennial Modern Classics.

Pinker, Steven. 2013. Language, Cognition, and Human Nature: Selected Articles. Oxford: Oxford University Press. 
Quirk, Randolph, Greenbaum, Sidney, Leech, Geoffrey and Svartvik, Jan. 1985. A Comprehensive Grammar of the English Language. London and New Yourk: Longman.

Sag, Ivan A. 2012. Sign-Based Construction Grammar: An Informal Synopsis. In Hans C. Boas and Ivan A. Sag (eds.), Sign-Based Construction Grammar, pp.69-202. Stanford: CSLI.

Tomasello, Michael. 2003. Constructing a Language: A Usage-Based Theory of Language Acquisition. Harvard: Harvard University Press.

Traugott, Elizabeth Closs. 1989. On the Rise of Epistemic Meaning in English: an Example of Subjectification in Semantic Change. Language, 65, pp. 31-55.

Trousdale, Graeme. 2013. Multiple inheritance and constructional change. Studies in Language, 37:3, pp. 491-514.

Wärnsby, Anna. 2002. Modal constructions? The Department of English in Lund: Working Papers in Linguistics, 2.

Wärnsby, Anna. 2006. (De)coding modality: The case of must, may, måste and kan. In Marianne Thormählen and Beatrice Warren (eds.), Lund Studies in English.113. Lund: Lund University. 